\title{
Review of Wolfgang Iser and His Reception Theory
}

\author{
Yanling Shi \\ Shanghai International Studies University, Shanghai, 200083, China; \\ QuFu Normal University, Rizhao, 276826, China
}

\begin{abstract}
Wolfgang Iser is one of the famous advocates of Reception Theory in contemporary literary field. His Reception Theory is different from another famous advocate Jauss in many ways. This paper attempts to give an in-depth analysis of Wolfgang Iser and probes into his Reception Theory in the following seven aspects: the production of meaning; the implied reader model; the functionalist model of the text; processing the text: a phenomenology of reading; literature and communication: interaction between text and reader; Iser's literary anthropology; and reception theory meets cognitive criticism.
\end{abstract}

Index Terms - Wolfgang Iser, reception theory, text, reader

\section{INTRODUCTION}

Wolfgang Iser (July 22, 1926-January 24, 2007) was a leading German literary theoretician and co-founder of the Constance School of Reception Aesthetics, professor Emeritus of English and Comparative Literature at the University of Constance and the University of California, Irvine. When Iser died in 2007 in his eighty-first year he was one of the most widely known literary theoreticians in the world. Together with Hans Robert Jauss he had founded the Constance School of Literary Theory. His books had been translated into countless languages; he had taught and lectured all over the world and was honored by multiple honorary doctorates and prestigious memberships.

After the Second World War he studied English, German and philosophy at Leipzig University, the University of Tübingen in the French Occupation Zone then later in Heidelberg University, which was under American administration at the time. His major theoretical works include: 1) His PhD dissertation appeared in German only: Die Weltanschauung Henry Fieldings (Henry Fielding's World View, 1952). Inspired by Wilhelm Dilthey's three types of world views and Karl Jaspers's (1883-1969) psychology of world views, and driven by a determination to give the welter of details connected with and relevant to his project some overall structure, he produced a thorough and detailed analysis of the intellectual, theological, social and historical context in which Fielding worked. 2) Walter Pater. Die Autonomie des Ästhetischen (1969), appeared in English translation as Walter Pater. The Aesthetic Moment (1987). His "Habilitation", the book that would qualify him for a professorial position within the German system. 3) The Implied Reader. Patterns of Communication in Prose Fiction from Bunyan to Beckett (1974). 4) The Act of Reading. A Theory of Aesthetic Response (1978). 5) Prospecting: From Reader Response to Literary Anthropology (1989). 6) The Fictive and the Imaginary. Charting Literary Anthropology (1993), a book in which he is trying to clarify the function of literature in our fraught efforts to understand the world. Later he broadened his approach into what he came to call "literary anthropology", a theoretical tour de force into the fundamental modes of our mental operations and their role in human culture. So come 7) The Range of Interpretation (2000) and 8) How to Do Theory (2006). (Schlaeger, 2010).

\section{DIFFERENCES BETWEEN ISER AND JAUSS}

The reception of Wolfgang Iser's work was determined largely by general cultural factors, and to an extent it parallels the response to Jauss's writings. The similarities in the German reception of the reception theory should not obscure their fundamental differences. Although both have been concerned with a reconstitution of literary theory by drawing attention away from the author and the text and refocusing it on the text-reader relationship, their respective methods of approaching this shift have diverged sharply. (1) While the Romance-scholar Jauss was initially moved towards reception theory through his concern for literary history, Iser, a scholar of English literature, comes from the interpretative orientations of New Criticism and narrative theory. (2) Whereas Jauss depended at first on hermeneutics and was particularly influenced by Hans-Georg Gadamer, the major impact on Iser has been phenomenology. Particularly important in this regard has been the work of Roman Ingarden, from whom Iser adopts his basic model as well as a number of key concepts. (3) Finally, even in his later work Jauss is most often interested in issues of a broad social and historical nature. His examination of the history of aesthetic experience, for example, is developed in a grand historical sweep in which individual works have chiefly an illustrative function. Iser, by contrast, is concerned primary with the individual text and how readers relate to it. Although he does not exclude social and historical factors, they are clearly subordinated to or incorporated in more detailed textual considerations. In Jauss is thought of as dealing with the macrocosm of reception, then Iser concerns with the microcosm of response. 


\section{ISER'S RECEPTION THEORY}

Roland Barthes put forward the famous proclamation of "the death of the author" in the 1960s. Iser's work in the realm of reception theory stands as his most significant contribution to literary theory. The background of Iser's own search for answers was the conviction that the literary text as an example for the aesthetic had a function radically different from other types of discourse and that in the text-reader relationship too much had been taken for granted, or not taken into account at all, by traditional criticism.

Reception theory was a reaction to what appeared to be a stalemate in literary studies. Of paramount concern for this theory was the impact a piece of literature has on its readers and the responses it elicits. Instead of asking what the text means, I asked what it does to its potential readers.... The message (of the text) that was no longer to be ascertained triggered interest in what has since been called text processing-what happens to the text in reading. (Iser, 2000, p. 311)

This is the decisive shift in literary theory; it is a shift from meaning to the aesthetic processes constituting it:

Consequently, aesthetic response, as the hallmark of reception theory, is to be conceived in terms of interaction between text and reader. I call it aesthetic response because it stimulates the reader's imagination, which in turn gives life to the intended effects. (Iser, 2000, p. 311)

\section{(1) The Production of Meaning}

The final chapter in The Implied Reader, "The Reading Process: A Phenomenological Approach" is important. Iser states that there are "two poles" in a literary text: "the artistic refers to the text created by the author, and the aesthetic to the realization accomplished by the reader." Somewhere between the poles is "the literary work," which readers create by reading or realizing a text. (Iser, 1974, p. 274)

What interest Iser is the question of how and under what conditions a text has meaning for a reader. In contrast to traditional interpretation, the widely practiced "digging-for-meaning-approach", which has sought to elucidate a hidden meaning in the text, he sees meaning as the result of an interaction between text and reader, as "an effect to be experienced," not "an object to be defined." Ingarden's conception of the literary work of art thus provides a useful framework for his investigations. For if the aesthetic object is constituted only through an act of cognition on the part of the reader, then the focus is switched from the text as object to the act of reading as process.

The literary work is a combination of text and the subjectivity of the reader. Accordingly Iser maps out three domains for exploration. The first involves the text in its potential to allow and manipulate the production of meaning. Like Ingarden, Iser regards the text as a skeleton of "schematized aspects" that must be actualized or concretized by the reader. Second, he investigates the processing of the text in reading. Of central importance here are the mental images formed when attempting to construct a consistent and cohesive aesthetic objectivity. Finally, he turns to the communicatory structure of literature to examine the conditions that give rise to and govern the text-reader interaction. In considering these three areas Iser hopes to clarify not only how meaning is produced, but also what effects literature has on its reader.

\section{(2) The Implied Reader}

Critics have put forward various models of the reader. These models contain special qualities of the reader, and illustrate special theories about reader and reading. For example, the familiar models include the "mock reader" put forward by Gibson, the "implied reader" by Wayne Booth, the "implied reader" by Iser, the "historical reader" by Jauss in 1980, the "ideal reader" created by J. Culler, "the informed reader" proposed by S. Fish, and "the transactive reader" proposed by N. Holland, etc.

An early model of the reader was proposed by W. Gibson, the "mock reader." Gibson begins his argument with a denunciation of the real author whom he regards as "distracting", "mysterious," and "irrelevant", and looks for the "fictitious speaker" in the text. There is an addresser in the text whose voice is heard in the reading process; therefore, an addressee exists, participating in the dialogue with the addresser. The fictitious addressee or "the mock reader" is a theoretical construct and he listens to the fictitious author and agrees with the latter. In the early 1950s the theory of "mock reader" is the first effort that shifts critical attention from the text to the reader and establish a heuristic model of the reader for a reading theory.

W. C. Booth further elaborated the difference between the real author and the fictitious speaker in The Rhetoric of Fiction (1961). He argues that the real author creates an "implied author" in the text who is "an implied version" of himself, and his presence is felt through the values and beliefs shown in the work, and the reader must construct his image if he is to respond to the various commitments of the implied author. Booth argues that the real author, in the process of creating his alter ego, or second self, also creates a counterpart of the real reader. The most successful reading is one in which the created selves, author and reader, can find complete agreement.

Wolfgang Iser puts forward a different model even it has the same name of "the implied reader." In The Act of Reading, Iser defines "the implied reader" as: "If, then, we are to try and understand the effects caused and the responses elicited by literary works, we must allow for the reader's presence without in any way predetermining his character or his historical situation. We may call him, for want of a better term, the implied reader. He embodies all those predispositions necessary for a literary work to exercise its effect — predispositions laid down, not by an empirical outside reality, but by the text itself. Consequently, the implied reader as a concept has his roots firmly planted in the structure of the text; he is a construct and in no way to be identified with any real reader." (Iser, 1978, p. 34) In The 
Implied Reader, the implied reader is defined as both a textual condition and a process of meaning production: "The term incorporates both the prestructuring of the potential meaning by the text, and the reader's actualization of this potential through the reading process." (Iser, 1974, p. xii) The "textual structure" of the implied reader is composed of three basic components: the textual perspectives, their convergent place, and the vantage point of the reader. The convergent place and the vantage point of the reader are to be actualized by the real reader; otherwise, they remain potential in the textual structure. The "structured acts" of the implied reader made the actualization possible. In iser's opinion, the text gets its meaning only when it is read; so the literary work becomes meaningful only with the engagement of the reader. With the concept of the implied reader, the two components the reader and the text are not looked upon as separate entities any more. They are the two sides of a coin and they are united into an organic whole. Therefore, with the reader-text interaction, literary communication appears. Consequently, the implied reader can be comprehended as a phenomenological construct of the actual reader. The "textual structure" of the implied reader is homologous to the response-inviting structure of the text. The "structured acts" of the implied reader is a response-projection mechanism in the reader. That is to say, confronted with the appeal structure of the text, the reader has the feeling of being forced to involve himself in the interaction with the text, in order to actualize the potential meaning.

\section{(3) The Functionalist Model of the Text}

The distinguishing feature of literature is that it deals with conventions in a different manner. Literature tells us something about reality by ordering its conventions so that they become objects of our reflection. Iser refers to these conventions as the repertoire of the text. It is the "familiar territory" on which text and reader meet to initiate communication. "The repertoire consists of all the familiar territory within the text. This may be in the form of references to earlier works, or to social and historical norms, or to the whole culture from which the text has emerged." (Iser, 1978, p. 69) Through the repertoire, the literary text reorganizes social and cultural norms as well as literary traditions so that reader may reassess their function in real life. A text should be understood as "a reaction to the thought systems which it has chosen and incorporated in its own repertoire." (Iser, 1978, p. 72) The repertoire assumes a dual function in Iser's model: "it reshapes familiar schemata to form a background for the process of communication, and it provides a general framework within which the message or meaning of the text can be organized." (Iser, 1978, p.1) The repertoire includes mostly elements that have been traditionally considered "content." As such, it needs a form or structure to organize its presentation, and Iser adopts the term "strategies" to designate this function. Strategies are not mere structural features, rather, they entail both the ordering of materials and the conditions under which those materials are communicated. In Iser's words, "They encompass the immanent structure of the text and the acts of comprehension thereby triggered off in the reader." (Iser, 1978, p. 86) These strategies should not be understood as a total organization, nor be viewed as traditional narrative techniques or rhetorical devices, they are instead the structures that underlie such superficial techniques and allow them to have an effect. "After all, the ultimate function of the strategies is to defamiliarize the familiar." (Iser, 1978, p. 87)

\section{(4) Processing the Text: A Phenomenology of Reading}

A modern philosophical trend emphasizing the perceiver's central role in determining meaning is known as "Phenomenology." Of central importance for Iser's phenomenology is the concept of the "wandering viewpoint." "The wandering viewpoint is a means of describing the way in which the reader is present in the text. This presence is at a point where memory and expectation converge, and the resultant dialectic movement brings about a continual modification of memory and an increasing complexity of expectation." (Iser, 1978, p. 118) The reader's travelling through the book is a continuous process of adjustments. We have in our mind some expectations, based on our memory of characters and events, but these expectations and imaginations are continually modified, and these memories are also transformed when we go through the whole text. What we get when we read is not something fixed and completely meaningful at every point, but only a series of continuously changing views.

\section{(5) Literature and Communication: Interaction between Text and Reader}

Iser's version of reader-response criticism, unlike that of Norman N. Holland, does not concern itself with investigating empirically the reactions of particular readers to literary texts. For Iser, a given text does not depend utterly upon any particular reader for its meaning but "implies" an ideal reader. Literary meaning inheres in a collaboration between author and reader. Iser draws upon the speech-act theory of J. L. Austin in regarding the author's words as providing instructions to the reader, who acts to fill in the gaps and blanks inevitably encountered in any serious literary text. It is gaps, blanks, indeterminacies and the "in-between" status of literary texts, it is the dialectics between presences and absences that structure his text models, and it is "oscillation" that characterizes the text-reader relationship.

"Blank" has occupied a central place in Iser's speculation. It is initially concerned with connecting various segments of the text. What this entails is perhaps most readily understood in considering the level of plot. In most narratives the story line will suddenly break off and continue form another perspective or in an unexpected direction. The result is a blank that the reader must complete in order to join together the unconnected segments.

\section{(6) Iser's Literary Anthropology}

What I have since called literary anthropology is thus a direct offshoot of reception theory, and it tries to handle the issues that the latter left dangling, because the function of literature is by no means entirely covered by its interaction 
with its readers and with its referential realities. Moreover, if a literary text does something to its readers, it simultaneously tells us something about them. Thus literature turns into a divining rod, locating our dispositions, desires, and inclinations and eventually our overall makeup. (Iser, 2000, p. 311)

With this programme Iser returns to a crucial component of his agenda: his fundamental epistemological skepticism, his firm conviction that all attempts to subsume the world under one overarching explanatory system are doomed to failure.

The anthropological significance of fictionalizing becomes unmistakable in relation to the many unknowable realities that underlie our existence. The beginning and the end are perhaps the most all-pervading realities of this kind. If fictionalizing transgresses those boundaries beyond which unrecognizable realities exist, then the very means we concoct to repair this deficiency - caught between our unknowable beginning and end - becomes indicative of how we conceive of what is withheld, inaccessible, and unavailable. (Iser, 2000, p. 311)

The world is ultimately unknowable, many important things seem to be unsayable, but literature overcomes these "deficiencies" and offers its readers the chance to transcend their limitedness — on one condition only, however: that we are always conscious in the process of reading of the conditionality of everything that takes us beyond ourselves. This is what Iser tried to encapsulate with the notion of negativity. Negation is one of literature's major strategies for shaking off the shackles of existing concepts of the real, but negativity is the fundamental anthropological condition which accompanies all our attempts to transcend them, to articulate what is ultimately always unsayable. Negativity is the gatekeeper of the other world to which we have access only in the provisionality of fictionalizing. For Iser negativity also drives the urge in human culture to invent ever new strategies for fictionalized self-extensions. Since all these strategies are stigmatized with the conditionality of their own fleeting existence they are intrinsically unstable. This instability is for Iser the main impetus for ever new attempts. We can't help doing it, but we know that it is ultimately at best provisional, in need of a controlling consciousness and instant repair. This is why we have to continue trying.

(7) Reception Theory Meets Cognitive Criticism

"Going cognitive" is a useful way to define a current tendency in literary studies. The term "cognitive" is omnipresent with "cognitive rhetoric", "cognitive stylistics", "cognitive poetics" and "cognitive theory". Some might say a "cognitive revolution" has come into being in literary studies.

We like to speak of reception theory when we refer to research in this field, a field with close relations with cognitive criticism. As Terence Wright argues, reader-response refers to "a variety of positions held together only by their concern with what goes on in the mind of the reader when he or she picks up and peruses a book." (Wright, 1995, p. 530) As such a statement may equally be applied to cognitive criticism, the genesis of these two related areas of research is worth our exploration.

In the essay, "From Iser to Turner and Beyond: Reception Theory Meets Cognitive Criticism", professor Craig A. Hanulton and Ralf Schneider (2002) critically reviewed the work of Wolfgang Iser and Mark Turner, two important figures with relation to reception theory and cognitive criticism, and discussed the similarities and differences between lser and Turner. They argue that cognitive criticism should not ignore its roots in reception theory and suggest how a cognitive reception theory can be constructed.

\section{A SUMMARY TO ISER'S RECEPTION THEORY}

The contemporary critic and theorist Wolfgang Iser analyses the phenomenological aspect of the reading process put forward by Roman Ingarden. However, there are great differences between the two. Ingarden just makes a general description of the reading process, whereas Iser broadens his study and applies his theory to many specific literature works, even prose fiction. According to Iser, any literary text is a product of the writer's intentional acts, and it partly controls the reader's response, however, it includes a great deal of "gaps" or "indeterminate elements". In order to understand much better, the reader must take an active participation, and try to fill in these gaps creatively, with the given information in the text before him. The whole reading experience thus becomes an evolving process of anticipation, frustration, retrospection, reconstruction, and satisfaction. Iser makes a distinction between the implied reader and the actual reader. The implied reader is formed within the text, and he is expected to respond in many specific ways to the "response-inviting structures" of the text. The actual reader, however, with his own personal experiences accumulated little by little, his responses actually are continuously and inevitably changed and reconstructed. Consequently, literary texts always take on a range of possible meanings according to Iser's analysis.

Iser presents the text as a potential which is "concretized" by the reader according to their different extra-literary standards, views, values or personal experiences. A sort of oscillation is set up between the power of the text to control the way it is read and a reader's "concretization" of it in terms of his or her own experience-an experience which will itself be modified in the act of reading. Meaning exists in the continuous adjustments and reconstruction to expectations. These revisions are caused in the reader's mind in the reading process while they are trying to make sense of his dialectical relationship to the text.

The emphasis in Iser's analysis is fundamentally phenomenological, because what is at the center of the literary process is the reader's reading experience. By resolving the contradictions between the various viewpoints which emerge from the text or by filling the "gaps" between viewpoints in various ways, the readers take the text into their consciousnesses and make it their own experience. 
Iser's works can serve both as a catalyst for a thoroughgoing analysis of the present state of theory as well as a springboard for an overhaul, long overdue, of the model of the mind that still governs most research paradigms in the humanities today.

\section{REFERENCES}

[1] Hanulton, Craig A. \& Ralf Schneider. (2002). From Iser to Turner and Beyond: Reception Theory Meets Cognitive Criticism, Style, Volume 36, Number 4, Winter, 640-658.

[2] Holub, Robert C. (1984). Reception Theory: A Critical Introduction. London and New York: Methuen.

[3] Iser, Wolfgang. (1974). The Implied Reader. Patterns of Communication in Prose Fiction from Bunyan to Beckett. Baltimore and London: The Johns Hopkins University Press.

[4] Iser, Wolfgang. (1978). The Act of Reading: A Theory of Aesthetic Response. London and Henley: The Johns Hopkins University Press.

[5] Iser, Wolfgang. (2000). Do I Write For an Audience? PMLA, 115: 3 (May), 310-314.

[6] Schlaeger, Jurgen. (2010). Wolfgang Iser: Legacies and Lessons, Comparative Critical Studies 7.2-3, 311-324.

[7] Selden, Raman, Peter Widdowson, \& Peter Brooker. (2004). A Reader's Guide to Contemporary Literary Theory. Beijing: Foreign Language Teaching and Research Press.

[8] Wright, Terrence. (1995). Reader-Response under Review: An Art, A Game, or A Science? Style 29, 529-548.

[9] Zhu Gang. (2001). Twentieth Century Western Critical Theories. Shanghai: Foreign Language Education Press.

[10] Zhu Gang. (1998). On Wolfgang Iser's “Implied Reader”. Contemporary Foreign Literature, 8, 152-157.

[11] Zhu Gang. (1999). From Text to Literary Works_- Iser's Phenomenological Concept of Text. Foreign Literatures, 2, $26-45$.

[12] Zhu Gang. (1998). Uncertainty and Dynamic Character in Literary Reading_-Iser's Phenomenological Reading Model. Foreign Literature Review, 3, 108-114.

Yanling Shi is a Ph. D. candidate at Shanghai International Studies University, Shanghai, China, 200083. She is also lecturer at East Languages and Translation Studies School of QuFu Normal University (Rizhao 276800, China). 